\title{
Implementing registration within a health organisation setting
}

\author{
Erica Henderson and Kim Fry
}

Erica Henderson is the Professional Adviser for Social Work at MidCentral Health and the Gateway Coordinator for MidCentral Health. Kim Fry is the Regional Director of Allied Health for MidCentral Health and Whanganui District Health Board. She was the Professional Adviser for Social Work at MidCentral Health for 2001-2009.

\section{Abstract}

This article tracks the journey MidCentral Health took after the introduction of the Social Workers Registration Act (2003). The accomplishments and the challenges that we encountered along the way indicate the importance of engaging the entire organisation to raise awareness and support for health social workers to not only achieve registration but stand alongside our regulated colleagues.

\section{Introduction}

MidCentral Health $(\mathrm{MCH})$ is the provider arm of the MidCentral District Health Board. The main hospital and services are situated in Palmerston North. There are currently 52 social workers employed at MidCentral Health in various services. They are supported by a Professional Adviser of Social Work (PASW) who works in partnership with service managers. Prior to the Social Workers Registration Act (2003) (SWRA) most social workers at MCH were members of Aotearoa New Zealand Association of Social Workers (ANZASW) and many were active members of the local branch. There was a strong ongoing commitment to the social work profession and in particular the development of a professional health social work culture. Registration was seen as a logical next step.

\section{The story so far}

During the early 2000s there was much debate and discussion within the social work profession nationally around the progression towards a registration framework. As Beddoe and Deeney (2012) note, the health environment was influenced during that era by a prevailing business model which presented social workers with both challenges and opportunities. At $\mathrm{MCH}, 2001$ saw the establishment of the PASW position. In addition to this being a response to the need for clinical leadership alongside new management models, it also acknowledged the status of social work alongside our allied health colleagues.

For health social workers the national discussion around registration was occurring in an environment where many of our health colleagues were undergoing changes to their regulatory legislation. These changes led to the Health Practitioners Competency Assurance Act (2003) (HPCA). Both the HPCA and the SWRA sought to provide public safety and an ongoing competency framework for regulated staff. However, due to both acts being developed 
simultaneously concerns for health social workers were that we would be seen as second-tier health professionals because we were not covered under the HPCA (Briggs \& Cromie 2001). This concern came to fruition with the Protected Quality Assurance Activities (PQAA) whereby according to the HPCA these could only be held with, '... health practitioners registered under the Health Practitioners Competence Assurance Act 2003' (Ministry of Health 2004). Social workers and other professions not under HPCA were initially excluded from PQAA whereas prior to the HPCA we would have sat alongside our colleagues. Previously, for example, this activity would have occurred at Multidisciplinary Team meetings (MDT); however, we were finding ourselves excluded and challenged about our attendance.

Nationally the district health board (DHB) social work leaders raised and clarified this concern with the Ministry of Health, enabling both ourselves and our self-regulating colleagues to be involved with PQAA if required.

The second concern was the voluntary nature of the SWRA. While at MCH the passing of the Act was welcomed by the health social workers, we were aware that the voluntary nature of the Act could be perceived as a rationale for management within the organisation not to support staff to achieve this. Indeed this was the case for some DHBs and still is today. In 2007 during the five yearly review of the Act, the national DHB social work leaders' council strongly recommended registration become mandatory, in order for us to be seen as equivalent to our health colleagues. The Health and Disability Commissioner's submission to the 2007 review also noted that although social workers are accountable under the Code of Health and Disability Services Consumers' Rights:

... the options for taking action against social workers who are found to be in breach of the Code are more limited if the social worker is unregistered. In my view, the mandatory registration of social workers would significantly improve the ability to take appropriate action to protect consumers when faced with serious complaints about a social worker's conduct (Social Work Registration Board 2007: 35).

In 2004, after the SWRA was passed the then PASW developed a course of action to work with senior management and social workers at $\mathrm{MCH}$ to ensure that there was an agreed approach to registration. Initially this involved meetings and presentations to management and leaders to discuss the rationale for supporting social workers to be registered. This approach relied on highlighting the multi-professional environment and the need to endorse registration alongside colleagues who were now under the HPCA. Approval by $\mathrm{MCH}$ managers was assisted by emphasising that both legislative acts had a public safety intention. On reflection the PASW received overwhelming support from senior managers and social workers and no obvious barriers to implementation were raised.

Once support had been received from managers, the PASW developed an agreed plan to implement registration within $\mathrm{MCH}$. This plan outlined the steps and support for social workers which included a dedicated time allowance for current social workers to work towards registration. As with most new developments, polices and procedures were also developed to provide a framework for staff and their managers. The policy and the procedure were also a vehicle to further raise awareness with staff and managers during the consultation process. Both these documents were endorsed by the clinical board who have a clinical governance function in the organisation, ensuring social work registration sits within this framework as well. 
Another action to ensure social work registration was embedded was to have social work job descriptions include the need to 'have or be eligible for social work registration' included in the essential requirements.

In order to maintain social workers' commitment to achieving registration several actions were undertaken. Firstly the PASW raised the need for registration at professional meetings regularly, secondly Buster Curson, the then Chairperson of the Social Work Registration Board (SWRB), was invited to speak to social workers and thirdly a regular communiqué and survey was sent out to staff to monitor progress The survey asked the social workers if they had applied to the SWRB, and if not, where were they at in the process, e.g. there were staff who had to get overseas qualifications verified and others who were awaiting ANZASW competency. This survey also acted as a reminder to social work staff regarding the process and the progress of registration and enabled the PASW to follow up with individuals to assist as needed. Regular reports to managers of the progress were also delivered.

Any assistance that could be provided to ease the process for social workers was undertaken, such as arranging for a justice of the peace to be available at a set time for social workers to get their paperwork legally certified.

The issue of mandatory registration was again discussed during the 2011 review of the SWRA and social workers at MCH were still in support of this occurring. The review outcome of a recommendation to mandatory registration being made to the Minster of Social Development gave us hope. However, there was an expectation that the Government's White Paper for Vulnerable Children (Ministry of Social Development, 2012a) would formally support compulsory registration for social workers. But to widespread disappointment from DHB social workers, that support was not forthcoming; rather, the recommendation was focused on the Child Youth and Family social work force.

The social work workforce also needs improvement through strengthening social work knowledge, skills and accountability. This can be achieved through improved supervision, performance management and training and strengthened accountability through Child Youth and Family requiring all its frontline social workers to be registered (Ministry of Social Development 2012b: 112).

ANZASW suggested last year that the Children's Action Plan (Ministry of Social Development, 2012b) will contain actions to promote and support social worker registration, for example through employment and funding contracts and through audit obligations (ANZASW Annual Report 2011/2012). The SWRB's unswerving advice to Government recommends an amendment to the SWRA to provide for a mandatory system of social worker registration through the protection of title "Social Worker". Only protection of title will ensure, '... that functions performed by social workers cannot be performed by unregistered persons" (SWRB 2007: 13). As the years have progressed, social work registration has been seen as an important tool to ensure equal opportunity for social work as a profession within $\mathrm{MCH}$. Indeed, a social worker recently commented on the added value that registered social workers provide, and are acknowledged by their colleagues as providing, to wider multidisciplinary teams. Registration has also allowed social workers the opportunity to ascend the ladder of hospital clinical management, providing a career pathway into management as well as clinical leadership within health. In this context, it is also important to note that there are an increasing number of positions / roles within our DHB that require an applicant to be a 
registered health professional - for example, an Autism Spectrum Disorder coordinator role, an adolescent and young adult coordinator role with oncology services, and within $\mathrm{MCH}$, Clinical Educator and Professional Development roles.

\section{Challenges along the way}

There were several challenges with the implementation of social work registration, one of which was the definition of 'social worker'. Some positions within the organisation were (and still are) generic positions that could be filled by any professional discipline. This was most common in the mental health services. Situations sometimes arose where applicants with a social work qualification and experience would be appointed without the involvement of the PASW. Although the policy had been signed off at a clinical board level, there was still some misunderstanding over what social work registration meant at an operational level. This is partly due to the different process social workers have for gaining registration compared to our health colleagues. There was an assumption that comparable with our colleagues in other professions we could achieve registration after gaining our tertiary qualification. This situation created further confusion for managers, with the variety of tertiary education providers which offer social work qualifications and a lack of clear guidance around overseas qualifications.

Related to this matter was our local situation and the tertiary institutions from which our new social workers (and students) graduated. In the Manawatu we had two main social work education providers - Massey University and Te Wananga O Aotearoa. Up until 2012 only Massey University graduates (both BSW and MSW applied) met the criteria for registration; however, we had previously been taking graduates and students from both institutions. This issue of qualification had been debated in the national social work arena, especially in relation to some rural communities who had providers that did not produce recognised qualifications. The concern was that by, '... setting the standard at degree level appears to reinforce traditional, positivist ideas about what is acceptable knowledge' (Pitt 2005: 41).

It is interesting to note that the tertiary providers Pitt refers to have now either had their degree programmes recognised by SWRB or developed agreements with larger providers for a pathway into recognised degree programmes (Beddoe \& Duke 2009). This has occurred with our local provider, Te Wananga $\mathrm{O}$ Aotearoa having their social work programme recognised by the SWRB.

Another challenge was to our previous processes of occasionally employing a student on successful completion of a placement with us, straight after gaining their qualification. This meant we had to negotiate a timeframe for the staff member to achieve registration. The requirement to complete 2000 hours and undertake competency required planning and agreement with the new graduate social worker and their manager early on in their appointment. To deal with this the procedure outlined processes and timeframes. However, due to the timeframe (2000 supervised practice hours equates to 50 weeks in a 40 -hour week) there were situations when this was problematical to monitor. The introduction by the SWRB of provisional registration after the review of the Act in 2007 greatly assisted with this.

Further challenges were working with staff who gained registration under section 13. $\mathrm{MCH}$ had several staff that fitted this requirement and for some of them the process felt not 
only daunting but highlighted to them their differences from colleagues. Part of the anxiety for these staff was also the initial common belief around needing to gain a social work qualification. We were aware from colleagues in Child, Youth and Family Services (CYFS) that this was occurring for some of their staff. Working alongside our staff members to apply under section 13, the PASW and managers were able to reassure them that they would not have to undertake further study (bearing in mind that many of these staff were nearing retirement it was not realistic) nor would they lose their jobs. Discussions with these social workers were undertaken to reassure them that they were not second class social workers and the intent of section 13 was to acknowledge the competencies and skills they had as social workers.

Ongoing challenges include a lack of personal commitment to, or belief in, the value of registration, for example some staff believing that due to the years of being unregulated it is another unnecessary bureaucratic process. There is also a reluctance to commit the necessary time and energy and a lack of necessary confidence to undertake the process, as stated earlier.

The work-loads within a hospital setting and consequent issues of time management also impact negatively on registration application rates. Although we initially supported social workers allocating work time to undertake registration, this is not overtly made available to social workers currently.

Financial concerns present other barriers, especially for some social workers. Current $\mathrm{MCH}$ reimbursement protocols have meant that registration fees must be met up front by the social worker. For many this is a challenge and there needs to be some discretion at a senior management level regarding pre-payment of registration, competency fees and annual practising certificates (APC). For some social workers, however, it is a personal embarrassment to request this.

MidCentral's experience highlights the need for ongoing education to ensure that social workers are clear about the difference between a crown entity (and public watchdog) and our professional association with its politically independent voice. For many social workers in Aotearoa New Zealand, competency is their primary focus and the current relatively complex arrangements of having two providers of competency, the ANZASW and SWRB is confusing and difficult for new staff and managers to grasp. While this is becoming easier as the two processes become more user friendly, it presents a barrier to registration for some staff who interpret registration as an act of disloyalty to the professional association.

Finally, it is equally important to note that the shift towards a more regulatory approach has brought a concomitant change to the role of PASW. The role has become much more 'supervisory' as we work to ensure that there is compliance with DHB registration policy. The current goal of $100 \%$ registered social workers within our DHB is a challenge for the PASW to maintain given the turnover of staff and the ability to recruit suitably qualified and registered social workers.

\section{The story today}

In the current environment in Aotearoa New Zealand, most district health boards require social workers to be registered. Being registered still affords health practitioners status and parity with other health professionals who are required to be registered under the HPCA. 
There is significant commitment to registration of social workers within the district health board setting. A survey carried out by the chair of the Social Work DHB Leaders Council indicated that of the 19 (out of the 20) DHBs which responded, 15 had policies which required social workers to be registered. The survey noted that $17 \mathrm{DHBs}$ provided financial support for registration and 14 provided support for new graduate social workers to become registered. Three DHBs required new graduates to have been provisionally registered under section 13 of the SWRA prior to commencing their employment and the one DHB who did not mandate compulsory registration still made provision for supporting social workers who came to the DHB already registered.

Of the several DHBs who do not currently have policies to support registration or require staff to be registered, two DHBs are currently formulating policies that would make registration compulsory for their social workers. The survey also noted that like the $\mathrm{MCH}$ experience, making registration compulsory within a DHB is a lengthy process because support for it must be engendered from clinical and operational governance structures within the organisation.

The survey revealed a number of difficulties that DHBs encountered when making registration mandatory and a number of inconsistencies. Firstly, while a DHB policy must ensure that it has provisions for employing social workers under section 13 of the SWRA, DHBs must also make provision for social workers returning to work and for overseas applications seeking employment in Aotearoa New Zealand. Some DHBs have given themselves scope to circumvent their own registration policy to hire a social worker who has come from the NGO sector if they have the right skills or ethnicity. While this decision makes sense in some respects we acknowledge this would not occur with other health professionals. Secondly, policies and management support must also anticipate those instances where social workers refuse or avoid registration or where people let their competency lapse (M. Derrett, personal communication, March 18, 2013).

Where policies exist to support registration for all social workers, most DHBs have provision to reimburse social workers for registration and competency through their current multi-employer collective agreement. Currently, social workers are required to prepare for registration in their own time, just as they are personally responsible to ensure that their Annual Practising Certificate is up to date. In this mandatory climate, registration has become the default, and the most important, standard for social work qualification - the quality and level of a social worker's tertiary qualification has therefore become secondary.

\section{The future}

Registration is also an important issue for supervision and it is essential that supervisors and line managers within health collaborate to plan and support social workers' efforts to meet their professional requirements. MidCentral has laid a good foundation with its supervision policy which outlines the organisational and legislative requirements for Allied Health and Mental Health and incorporates the SWRB expectations and ANZASW policy on supervision for social workers. There is a significant role for the Professional Advisor of Social Work to keep abreast of any changes, to ensure the organisation meets legislative requirements, and maintains best practice. 
The SWRB prefers that social work supervisors will be registered and have completed training in professional supervision (Social Workers Registration Board 2011). The development, education and support of social work supervisors is an ongoing challenge for the DHB. There is, however, opportunity to work regionally, and MidCentral and Whanganui DHBs have recently supported joint training for supervisors in Allied Health and Mental Health.

There is also a gap for some social workers in adapting to the changing regulatory environment. The recent censure by the SWRB of registered social workers for not having current Annual Practicing Certificates highlights the fact that the SWRB are no longer willing to let things drift. The clear message in all this is that the SWRB expects social workers will comply with its strictures and will forcibly discipline those who do not. This then emphasises the need for DHBs to have clear policies and procedures to not simply support social workers at the beginning to register but also to provide ongoing monitoring and support.

Going forward there is a need for greater clarity about mandatory registration. All DHB social workers, particularly, need similar regulation to their colleagues in other health disciplines if we are going to enjoy any sense of professional parity of esteem.

The two separate competency processes that currently exist in tandem in Aotearoa New Zealand at this point require urgent streamlining if social workers are to continue engaging with both the ANZASW and the SWRB. There would be considerable merit if the current system was integrated into one competency system, administered by the SWRB giving us alignment with our colleagues who are under HPCA. However, there still needs to be a vehicle whereby social workers are supported to maintain their connection to the ANZASW. The challenge going forward is discovering a new form of meaningful engagement outside a competency based process with the ANZASW which is fully supported by DHB social workers, their supervisors, their managers and their professional leads.

\section{Conclusion}

MidCentral Health's experience has been similar in many aspects to the journey taken by most other DHBs. Its development of a policy about registration and its process of ensuring compliance with the policy and providing support for staff has largely mirrored those of other DHBs around the country. Issues of support and understanding of our process from the DHB management were overcome through engagement of key people

Significantly, social work staff within our DHB have generally been both supportive of the process of registration and understand its importance in maintaining professional parity with other health workers. This has been a key driver in gaining support from our colleagues as well as management. Alongside this was placing oversight of the policy in our clinical governance framework.

The importance of the PASW role is central to the development of MCH's process and success; the ongoing nature of the role needs close attention due to the continual changes as our regulation develops (e.g. provisional registration).

The challenges that presented along the way have been resolved but need constant monitoring, for example generic positions, changes of front-line managers and supporting 
those staff who do not have a registrable social work qualification. Some challenges that all DHBs face still remain and the issue of mandatory registration is high on this list.

\section{References}

ANZASW Annual Report 2011-2012.

ANZASW Supervision Policy. (2012).

Beddoe, L., \& Deeney, C. (2012). Discovering health social work in New Zealand in its published work: Implications for the profession. Aotearoa New Zealand Social Work 14 (1): 41-55.

Beddoe, L., \& Duke, J. (2009). Registration in New Zealand social work: The challenge of change. International Social Work 52 (6): 785-797.

Briggs, L. \& Cromie, B. (2001). Editorial - Registration issues for health social work; Will social workers become 'second tier' health professionals? Social Work Review 13 (2): 1.

Health Practitioners Competency Assurance Act 2003. New Zealand Government: Wellington.

Minister of Health. (2004). Protected Quality Assurance Activities under the Health Practitioners Competence Assurance Act 2003. Pamphlet, June 2004.

Ministry of Social Development. (2012a). The White Paper for Vulnerable Children. New Zealand Government: Wellington.

Ministry of Social Development. (2012b). Children's Action Plan. New Zealand Government: Wellington.

Pitt, L. (2005). Social work registration: Knowledge and power. Social Work Review 17 (3): 41-42.

Social Workers Registration Act 2003. New Zealand Government: Wellington.

Social Workers Registration Board. (2007). Social Work Registration Act 2003. Review Report.

Social Workers Registration Board. (2011). Supervision Expectations for Registered Social Workers. Policy Statement.

Social Workers Registration Board. (2012). Social Work Registration Act 2003. Review Report. 